\title{
"Consumer Behavior" Change We Believe in: Demanding Reduction Strategy for Endangered Wildlife
}

\author{
Zhao Liu ${ }^{1,2}$, Zhigang Jiang ${ }^{1,2,3^{*}}$, Hongxia Fang ${ }^{1}$, Chunwang $\mathbf{L i}^{1}$ and Zhibin Meng ${ }^{1,3}$ \\ ${ }^{1}$ Key Laboratory of Animal Ecology and Conservation Biology, Institute of Zoology, Chinese Academy of Sciences, Beijing, China \\ ${ }^{2}$ Graduate School of Chinese Academy of Sciences, Beijing, China \\ 'Endangered Species Scientific Commission of People' Republic of China, Beijing, China
}

*Corresponding author: Zhigang Jiang, Institute of Zoology, Chinese Academy of Sciences, Beijing, China, Tel: 86-10-64807268; E-mail: jiangzg@ioz.ac.cn

Received date: November 09, 2014; Accepted date: December 17, 2014; Published date: December 23, 2014

Copyright: $\odot 2014$ Liu Z, et al. This is an open-access editorial distributed under the terms of the Creative Commons Attribution License, which permits unrestricted use, distribution, and reproduction in any medium, provided the original author and source are credited.

\begin{abstract}
s
China has a history of using wildlife or for their parts and products, but now the sustainability use of endangered medicinal wildlife face challenges. Understanding the behavioral change and making effective behavioral change approaches and strategies are essential to strengthen demand reduction efforts on endangered wildlife products in China. The work described how we can make approaches and strategies to change consumer behavior to do this.
\end{abstract}

Keywords: Illegal wildlife trade; Understanding consumer behavior; Behavior change models; Marketing strategy

\section{Introduction}

In order to support wildlife protection, reduce market demand of illegal wildlife products, the Chinese government has been pioneering good practices and leading initiatives to tackle the supply of endangered species products traded and consumed illegally [1]. Come nearly 10 years, 930 case of smuggling endangered wildlife parts and products have been carry out criminal case and more than 10 thousand administrative cases have been investigated by law enforcement authorities of China. Through a series of special crackdowns and nationwide campaigns including "Migratory Bird Action", "Falcon Action", "Spring Thunder Action", "Flying eagle Action", "Sky Net Action" and so on, China have cracked down a batch of illegal wildlife trade and effectively protected forest and wildlife resources [2]. Chinese government has made ongoing and persistent efforts to carry out some special campaign such as "BirdLoving Week", "Wildlife Protection Awareness Month", and launched publicity and education by the mean of media propaganda such as establishing TV column for wildlife protection, inviting famous experts to CCTV to make comments on wildlife protection, illegal wildlife case exposed by media, running public service advertising and other propaganda means including billboards, brochure, mobile phone short message, web pages, official micro-blog [3].

In recent years, despite efforts undertaken by government, the media, and the Non-Governmental Organizations (NGOs) and other parties to combat the unsustainable consumerism, the consumption of high value wildlife products, including threatened species, has also risen rapidly with the fast growing economy and people's purchasing power [4]. Historically, responses to this problem have been predominantly regulatory and have involved the introduction of new and stronger legislation, the establishment of trade controls (including sanctions) within CITES (The Convention on International Trade in Endangered Species of Wild Fauna and Flora), and the applying of political and diplomatic pressure [5]. Despite the growing emphasis that has been placed in areas such as environmental education or community-based conservation in recent decades, there is as yet little literature on the subject of influencing human behavior and biodiversity conservation. And now, there need some increasing recognition of the need for more multifaceted responses [6]. Some studies indicated that consumers of traditional Chinese medicine (TCM) prefer products made from wild-source, believing they are more potent than farm-raised ones [7-9]. For example, consumers showed a willingness to pay considerably more for wild bear bile than farmed, and the ability of farmed bear bile to reduced demand for wild bear bile is at best limited and, may be have the opposite effect [9]. Therefore new ways must be found to understand the consumer behaviors and the driving factors as to why consumers use these products, and then we study the tools and patterns that might change and eliminate the motivations behind those consumer behaviors $[1,10,11]$.

Demand for wildlife parts and products will inevitably trigger consumer buying behaviors and transaction activity of wild animal in the market [12]. Human behavior is the key driver of major threats to biodiversity, so we need to recognize that conservation is not only about wild animals and plants but equally about people and their behavior [6]. Symposium of Changing Consumer Behavior to Reduce Demand for Illegal Wildlife Products was held in Beijing, China, from 25 to 26 March 2014. Government representatives, Commercial enterprise, Electric business, Consumer research firmexperts and NGOs includingTRAFFIC (The Wildlife Trade Monitoring Network), CWCA (China Wildlife Conservation Association), WWF (World Wild Fund for Nature) attended the meeting. The topic of the symposium was "Understanding the behavioral change and making effective behavioral change approaches and strategies in China". As a part of "Globe Action to Reject Illicit Trade in Wildlife Parts and Products" which was sponsored by TRAFFIC and WWF, the conference aimed to reduce the illegal demand of endangered wildlife products by the mean of experiences and insights of representatives from a variety of different background, and develop frontier and innovative interventions to tackle illegal wildlife trade. At the conference, experts confirmed the key strategy that influencing target consumers to change their preferences and purchasing behavior and 
reduce the demand of endangered species products consumed illegally [1].

\section{Understanding consumer behaviors}

Understanding the behavioral change, public attitudes towards consumption of species products, and taking appropriate behavior change approaches are essential to strengthen demand reduction efforts on endangered wildlife products in China [1]. For example, many factors influence consumer preferences and behaviors, including those in the wider and local environment. Understanding all the factors that influence the behavior you want to change is an essential starting point [11]. To do this, both individual consumers and consumers in their social and culture settings need to be researched [10]. Firstly, it is necessary to understand the micro-level factors shaping individual behaviors such as consumption need and motivations, personality, perceptions, behavioral learning, attitudes, habits, values and lifestyles. Secondly, the macro-level influence factors of reference groups and family, social class and status, and the culture must all be considered $[10,13]$. After fully understanding the factors affecting consumer behavior, specific "marketing strategies" must be undertaken to change behavior [13].

Research must involve factors such as the consumer needs and motivation, personality, consumer perception, consumer attitude, behavioral learning, group dynamics and socio-cultural factors [10]. Understanding the consumer's needs and motivation is the first step toward preventing unsustainable wildlife consumption [4]. The factors motivating wildlife consumption are complex and culturally rooted, and they include physiological motives (i.e have tonic effect) and psychogenic motives (i.e representing social status) $[4,10]$. And because consumers make decisions and take actions based on what they perceive to be reality, so it is important to understand how consumers see the world around us, and how people learn [10]. For instance, tiger bone was believed to be more effective in ancient tenets of TCM and tiger image was considered as a famous brand by public [7,14]; TCM manufacturers takes advantage of "brand effect" to use the tiger's image on plasters which produced a habitual thinking and even a conditional stimulus that tiger image was associated with the "Tiger Bone Plaster". Consumer attitude research has a pervasive impact on consumer behavior [10]. For example, consumers often prefer wild animal products to those from farms. This belief leads to price differential and profit margins that may continue to spur wild collection even after the introduction of farmed supplies [7-9]. And some surveys of public attitude demonstrated that Chinese people were generally supportive of wildlife tiger conservation [14-17]. In addition, social factors also play very important role to affect consumer behaviors [10]. A survey found that respondents saw "edible" wildlife as a kind of special treat for guests-providing wild meat at a meal represents social status and shows respect for and closeness to guests, and eating wild animals or consuming wildlife products can show your prestige and social status [4].

\section{Behavior change models}

A recently TRAFFIC report revealed that 'Five principles' need to be addressed for effective behavior change strategies in : an objective and science-based approach; wild and comprehensive stakeholder involvement; targeted solutions aimed at key user groups; drawing upon diverse expertise; and government-led implementation [1]. And according to behavior change models, theories and social marketing principles [18], the "Five steps approach" has been identified by
TRAFFIC to reduce demands for endangered wildlife products, the steps are: 1) identifying behaviors; 2) understanding the influences on audiences for such behaviors; 3) developing a practical model of influences for positive behavior change; 4) building a marketing strategy to motivate the desired behaviors; 5) campaign development and implementation [1,11]. Behavior change models, concepts and theories for Step 3 of TRAFFIC's 'Five Step Approach' to Demand Reduction can confirm the type of activities that might be undertaken to deal with different audiences (with a business audience specially) [1]. The mechanisms that determine consumer behavior can be illustrated by 'Needs-Opportunities-Abilities' (NOA) Model [19]. Consumers are shown to require a combination of needs (largely emotional motivators), opportunities (e. g. access to the goods they wish to consume) and the abilities (e. g. adequate discretionary income) in order to purchase a product. Demand reduction initiatives thus typically attempt to disrupt 'need', whereas supply reduction initiatives typically attempt to disrupt 'opportunity' or 'ability' [1]. Another fundamental theory of change for a social marking, or Pride campaign, based on the stages of behavior change models including: Knowledge, Attitude, Interpersonal Communication, Barrier Removed, Behavior Change, Threat Reduction and Conservation Results [20-22]. Behavior change can be crucial to improve the management and conservation of nature resource, which is evidenced by many practices in local communities in different countries [22-25].

\section{Conservation actions}

Awareness campaigns in the area of wildlife trade have focused very much on the provision of information to the public. However, one of the weaknesses of this approach is that information does NOT always lead to action [11]. Influencing human behavior is one of the hardest challenges faced by conservationists today. Tackling it will require not only a push towards evidence-based endeavor but also the willingness to learn from other research fields [6]. So it is necessary to carry out multi-disciplinary research, for example, the methods of consumer behavior and social psychology can be used to research the motivations and other influential factors that drive consumer buying behavior [10]. Research on irrational consumption behavior based on principles of behavior economics may provide a new perspective for solving the problems [26,27]. Behavioral economics applies psychological insights to economic models and help us understand why people so often deviate from assumed rational behavior in the 'real' world [11]. Social marketing strategy can be used as a powerful tool for publicity and education [13]. Behavior change we can believe in $[1,11,18]$, and there will be a long struggle between the sciencebased behavioral changing actions to influence human behavior for biodiversity conservation and the consequences of the old lifestyles, and also a long struggle between the enlightenment education of conservation biology and the belief according old tenets of traditional culture.

The tools and theory for developing social marketing campaigns for wildlife conservation were developed and tested in the late 1970 s $[22,28]$. Social marketing is the application of marketing principles used to sell products applied to "sell" ideas, attitudes, and behaviors to benefit the public good [22]. Recently, some studies demonstrate that focusing on and achieving behavior change was not only possible but relevant to a range of conservation issues [6]. A campaign applying social marketing strategy to protect the Sichuan Golden Snub-nosed Monkey in Gansu Province in China was initiated in an effort to inspire communities to protect forest habitat in the reserve, and quickly adopt fuel-efficient stoves. Results of this study show 
Citation: Liu Z, Jiang Z, Fang H, Li C, Meng Z (2015) "Consumer Behavior" Change We Believe in: Demanding Reduction Strategy for Endangered Wildlife. J Biodivers Endanger Species 3: 141. doi:10.4172/2332-2543.1000141

Page 3 of 3

significant increases in knowledge, attitudes, and interpersonal communication pre and post campaign [22]. The founding of another social marketing campaign implemented in southwest Madagascar demonstrated that the power and suitability of social marketing as a tool for encouraging fishers to give up destructive fishing methods and to improve the awareness and enforcement of local laws [23]. Social marketing 'Price' campaigns also can apply to numerous environmental problems and establish reciprocal for resource conservation, such as creating local Reciprocal Water Agreement for water and biodiversity conservation, promoting the benefits of payment for forest conservation and habitat of wildlife [24,25]. Therefore, the challenge is to mainstream these principles and techniques amongst conservation professionals, which would undoubtedly help make research about the human dimensions of biodiversity management and a more evidence-based conservation practices [6].

\section{References}

1. TRAFFIC (2014) Symposium of Changing Consumer Behavior to Reduce Demand for Illegal Wildlife Products.

2. State Forestry Administration of the People's of China (SFAPC) (2014) 9 units were titled as "Advanced group of tackling the trade of illegal trafficking of wild animals".

3. State Forestry Administration of the People's of China (SFAPC) (2014b) China set an example to the world through fighting illegal wildlife trade.

4. Wasser RM, Jiao PB (2010) Understanding the Motivations: The First Step Toward Influencing China's Unsustainable Wildlife Consumption. TRAFFIC East Asia, China.

5. Challender DW, Wu SB, Nijman V, MacMillan DC (2014) Changing behavior to tackle the wildlife trade. Frontiers in Ecology and the Environment 12:203-203.

6. Veríssimo D (2013) Influencing human behaviour: an underutilised tool for biodiversity management. Conservation Evidence 10: 29-31.

7. Gratwicke B, Bennett E, Broad S, Christie S, Dutton A, et al. (2008) The world cannot have wild tigers and eat them, too. Conservation Biology 22: 222-223.

8. Kirkpatrick RC, Emerton L (2010) Kill tiger to save them: Fallacies of the farming argument. Conservation Biology 24: 655-659.

9. Dutton AJ, Hepburn C, Macdonald DW (2011) A stated preference investigation into the Chinese demand for formed vs. wild bear bile. PLOS ONE 6: e21243.

10. Schiffman LG, Kanuk LL (2004) Consumer Behavior. Pearson Prentice Hall, New Jersey.

11. Zain S (2012) Behavior Change We Can Believe In: Towards A Global Demand Reduction Strategy For Tiger. TRAFFIC International.
12. Zhou ZH, Jiang ZG (2005) Features and impacting factors on trade of wildlife. Biodiversity Science 13: 462-471.

13. Kotler P, Roberto EL (1989) Social Marketing: Strategies for Changing Public Behavior. Free Press, New York.

14. Nowell K, Xu L (2007) Taming the Tiger Trade. TRAFFIC East Asia, Hong Kong.

15. Gratwicke B, Mills J, Dutton A, Gabriel G, Long B et al. (2008) Attitudes toward consumption and conservation of tigers in China. PLoS One 3: e2544.

16. Zhang L, Hua N, Sun S (2008) Wildlife trade, consumption and conservation awareness in southwest China. Biodiversity Conservation 17: 1493-1516.

17. Zhang L, Yin F (2014) Wildlife consumption and conservation awareness in China: a long way to go. Biodiversity Conservation 23: 1-11.

18. Darnton A (2008) UK GSR Behaviour Change Knowledge Review. Practical Guide: An Overview of Behaviour Change Models and Their Uses. Government Social Research Unit, London, UK.

19. Vlek C (2000) Essential psychology for environmental policy making. International Journal of Psychology 35: 153-167.

20. Vaughan PW, Rogers EM (2000) A staged model of communication effects: Evidence from an entertainment-education radio drama in Tanzania. The Journal of Health Communication 5: 203-227.

21. Jenks B, Vaughan PW, Butler PJ (2010) The evolution of Rare Pride: using evaluation to drive adaptive management in a biodiversity conservation organization. Evaluation and Program Planning 33: 186-190.

22. DeWan AA, Green KM, Li X, Hayden D (2013) Using social marketing tools to increase fuel-efficient stove adoption for conservation of the golden snub-nosed monkey, Gansu Province, China. Conservation Evidence 10: 32-36.

23. Andriamalala G, Peabody S, Gardner CJ, Westerman K (2013) Using social marketing to foster sustainable behaviour in traditional fishing communities of southwest Madagascar. Conservation Evidence 10: 37-41.

24. Martinez R, Green K, DeWan A (2013) Establishing reciprocal agreements for water and biodiversity conservation through a social marketing campaign in Quanda Watershed, Peru. Conservation Evidence 10: 42-47.

25. Green KM, DeWan A, Arias AB, Hayden D (2013) Driving adoption of payments for ecosystem services through social marketing, Veracruz, Mexico. Conservation Evidence 10: 48-52.

26. Dan A (2008) Predictably Irrational: The Hidden Forces that Shape Our Decisions. HarperCollins, New York.

27. Diamond P, Vartiainen H (2012) Behavioral Economics and Its Applications. Princeton University Press.

28. Butler PJ (1988) Saint Vincent Parrot (Amazona guildingii): the road to recovery. RARE Center for Tropical Bird Conservation, Pennsylvania. 